\title{
Expurgo de grãos de trigo em câmara de lona
}

\author{
Scouring of wheat in camera bag \\ Celso Finck $^{\text {I }}$ Kamila Santana ${ }^{\text {II }}$ Edilson Batista de Oliveira ${ }^{\text {III }}$ \\ Pedro Henrique Weirich Neto ${ }^{\mathrm{IV}}$ Luiz Cláudio Garcia ${ }^{\mathrm{I}{ }^{*}}$
}

\section{- NOTA -}

\section{RESUMO}

$O$ objetivo deste trabalho foi determinar o menor periodo de fumigação necessário para promover a mortalidade total de insetos adultos do gênero Sitophilus, em grãos de trigo submetidos à fumigação em câmara de lonas. O experimento foi implantado em uma unidade armazenadora de grãos, em Ponta Grossa - PR. $O$ delineamento experimental foi inteiramente casualizado, contendo seis tratamentos e dez repetições. Os tratamentos consistiram de diferentes periodos de exposição dos grãos de trigo à fumigação: 0; 12; 36; 60; 84 e 108h, dispostos em caçambas de caminhão envoltas em lonas (formando a câmara de lonas). Empregou-se o produto comercial Fertox ${ }^{\circledR}$ na forma de pastilhas, atendendo à dosagem de $6 \mathrm{~g} \mathrm{~m}^{-3} \mathrm{em}$ câmaras de $35 \mathrm{~m}^{3}$ cada. As repetições foram representadas por recipientes telados contendo 10 insetos adultos vivos do gênero Sitophilus, inseridos na massa de grãos da caçamba em diversos pontos e profundidades. A equação de regressão ajustada para descrever o comportamento da mortalidade de insetos (M) em função do período de fumigação (T) foi $M=6,6867+93,4694\left(1-e^{0,1645 T}\right)^{26,9607}$. A equação demonstra que $58,9 \mathrm{~h}$ após a aplicação do fumegante a mortalidade dos insetos foi de $100 \%$.

Palavras-chave: caçamba de caminhão, Sitophilus, período de fumigação.

\section{ABSTRACT}

The objective of this study was to determine the shortest time of fumigation to promote the total mortality of adult insects of the genus Sitophilus, in grains of wheat, undergoing fumigation in chamber of tarpaulin. The experiment was carried out in a grain storage unit in Ponta Grossa - PR. The experimental design was completely randomized, with six treatments and ten replications. Treatments consisted of times of exposure of wheat grain fumigation: zero; 12; 36; 60; 84 and 108 hours, in bucket trucks wrapped in tarpaulin (forming the chambers of tarpaulin). It was applied the commercial product Ferto $x^{\circledR}$ in tablets form, with the dosage of $6 \mathrm{~g} \mathrm{~m}^{-3}$ in each chamber of $35 \mathrm{~m}^{3}$. Repetitions were composed by cages with ten live adult insects of the Sitophilus genus each one, inserted into the grain mass in bucket trucks and arranged at various points and depths. The fitted regression model to describe the insect mortality behavior (M) according to the fumigation time (T) was $M=6.6867+93.4694\left(1-e^{0.1645 T}\right)^{26.9607}$. Equation shows that $58.9 \mathrm{~h}$ after application of the steam product the insect mortality is of $100 \%$.

Key words: bucket truck, Sitophilus, fumigation period.

A pós-colheita de grãos é um processo dinâmico que demanda conhecimentos específicos, tecnologia especializada e cuidados constantes. Entre esses cuidados, está a preocupação com a infestação causada por insetos pragas de produtos armazenados (LIMA JÚNIOR et al., 2012). Dentre os insetos pragas que atacam os grãos armazenados, os carunchos podem ser considerados os mais importantes, sendo os insetos do gênero Sitophilus (Coleoptera: Curculionidae) os mais conhecidos (STRELEC et al., 2012).

Segundo o decreto $\mathrm{n}^{\circ} 24.114$ do Ministério da Agricultura (BRASIL, 1934), são proibidos, em todo o território nacional, “[...] a importação, o comércio, o trânsito e a exportação: b) de insetos vivos, ácaros, nematoides e outros parasitos nocivos às plantas, em qualquer fase de evolução". Portanto,

${ }^{\mathrm{I}}$ Grão Limpo, Ponta Grossa, PR, Brasil.

IPrograma de Pós-graduação em Fisiologia, Melhoramento e Manejo de Culturas, Universidade Estadual de Ponta Grossa (UEPG), Ponta Grossa, PR, Brasil.

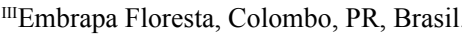

${ }^{\text {IV }}$ Departamento de Ciências do Solo e Engenharia Agrícola, UEPG, 84030-900, Ponta Grossa, PR, Brasil. E-mail: lcgarcia@uepg.br.com.

*Autor para correspondência. 
práticas de expurgo são de extrema importância para garantir a inexistência desses agentes e a qualidade do produto final. Dentre as várias modalidades de expurgo, a fumigação em câmaras de lona é a modalidade mais utilizada em aeroportos, portos e fronteiras (BERTUSSI, 2008).

No Porto de Paranaguá - PR os classificadores da CODAPAR seguem as Instruções Normativas 11, 38 e 60; considerando produto fora de tipo somente ao identificar inseto vivo, não levando em consideração ovo, larva ou pupa. Somente em relação ao feijão (Instrução Normativa 12), o percentual de ovos no tegumento pode caracterizá-lo como fora de tipo. Os grãos considerados fora de tipo devem ser submetidos a tratamento adequado e nova classificação, mediante certificado de expurgo. (CODAPAR, 2015; ZANIKOSKI, 2015 - Informe verbal).

A temperatura e a umidade relativa do ar no ambiente a ser expurgado são de extrema importância, pois determinarão a eficiência do processo, desaconselhando-se temperaturas abaixo de $10^{\circ} \mathrm{C}$ e umidade relativa do ar inferior a $25 \%$ (LORINI et al., 2007).

Em fumigação de grãos armazenados, FARONI \& SILVA(2000) asseveram que são necessários pelo menos $72 \mathrm{~h}$. A bula do produto comercial Fertox ${ }^{\circledR}$ recomenda que o período de exposição dos grãos ao fumegante deve ser de, no mínimo, 96h para arroz, cevada, aveia, milho, feijão e trigo (SEAB, 2013). LORINI et al. (2011) concluíram que o período mínimo de exposição das pragas à fosfina deve ser de $120 \mathrm{~h}$ com uma concentração do produto de 400ppm.

Levando em conta os custos do tempo em que os grãos comercializados não podem ser transportados com insetos vivos, este trabalho teve como objetivo determinar o menor período de fumigação necessário para promover a mortalidade total de insetos adultos de Sitophilus, em grãos de trigo submetidos à fumigação em câmara de lonas.

$\mathrm{O}$ experimento foi implantado na unidade armazenadora Celso Macedo Kossatz (25 $5^{\circ}$ 03' 44 ” S, $50^{\circ} 29^{\prime} 55^{\prime}$ W), localizada no município de Ponta Grossa - PR. O delineamento experimental utilizado foi o inteiramente casualizado, constituído por seis tratamentos e dez repetições. Os tratamentos consistiram de diferentes períodos de exposição dos grãos de trigo à fumigação: $0 ; 12 ; 36 ; 60 ; 84$ e $108 \mathrm{~h}$ após a aplicação de Fertox ${ }^{\circledR}\left(560 \mathrm{~g} \mathrm{~kg}^{-1}\right.$ de fosfeto de alumínio). $\mathrm{O}$ expurgo foi realizado em caçambas de caminhão envoltas em lonas (câmara de lonas).

O produto foi aplicado sob a forma de pastilhas, atendendo à dosagem de $6,0 \mathrm{~g} \mathrm{~m}^{-3}(2,0 \mathrm{~g}$ $\mathrm{m}^{-3}$ de fosfina). As caçambas utilizadas seguiram o padrão de 7,0 × 2,5 x 2,0m (comprimento, largura e altura), com câmara de $35 \mathrm{~m}^{3}$. As caçambas foram carregadas com aproximadamente 13 toneladas de grãos de trigo, recém-colhidos, limpos e secos, com umidade de $12 \%$ e peso hectolitro de 80 .

Consideraram-se como repetições recipientes plásticos distribuídos em diversos pontos e profundidades na massa de grãos, contendo 10 insetos adultos vivos do gênero Sitophilus - não sexados - provenientes de criação mantida em grãos de trigo. Os recipientes foram abertos na parte superior e inferior para permitir a passagem do gás, com tela metálica para impedir a fuga dos insetos. As laterais foram envoltas com fita adesiva para assegurar a não abertura da tampa.

Cada uma das armadilhas continha, além dos 10 insetos vivos, cerca de $20 \mathrm{~g}$ do mesmo trigo contido na caçamba, conforme as recomendações de SOUZA et al. (2012). Para a realização do expurgo e após a locação das armadilhas, realizou-se a vedação com lonas de polietileno, tanto do produto dentre as caçambas, quanto da caçamba como um todo, formando a câmara de lonas (BRASIL, 2006).

A aplicação do fumegante foi realizada às $7 \mathrm{~h}$ da manhã, e as caçambas/câmaras foram mantidas sob condições ambientais, monitoradas às $7 \mathrm{e} 19 \mathrm{~h}$ pelo termo higrômetro ICEL WM $1850^{\circledR}$. Após cada período estabelecido, a câmara de lonas foi aberta e contabilizouse o número de insetos mortos em cada recipiente.

Para descrição do comportamento da mortalidade dos insetos, em função do período decorrido após a aplicação do produto, foi utilizado o modelo de RICHARDS (1959). O modelo foi modificado pela introdução do parâmetro $\left(b_{0}\right)$ para absorver a influência da mortalidade existente no tempo "zero"; sendo expresso por: $\mathrm{M}=\mathrm{b}_{0}+\mathrm{b}_{1}\left(1-\mathrm{e}^{\mathrm{b} 2 \mathrm{~T}}\right)^{\mathrm{b} 3}$, em que $\mathrm{M}$ representa a mortalidade dos insetos (\%), $\mathrm{T}$ o período de fumigação (horas), e a base do logaritmo neperiano e $b_{0}, b_{1}, b_{2}$ e $b_{3}$ são coeficientes. Para cada tratamento, foram calculadas a média e o respectivo intervalo de confiança no nível de $0,05\left(\mathrm{t}_{0,05}\right)$.

Decorridas $36 \mathrm{~h}$ após a aplicação do produto, $6,0 \%$ de insetos ainda estavam vivos. A mortalidade dos insetos tem que ser completa para atender à legislação que proíbe a comercialização e transporte de produtos com presença de insetos vivos (BRASIL, 1934; CODAPAR, 2015).

A mortalidade de $100 \%$ dos insetos foi observada a partir de $60 \mathrm{~h}$ após a aplicação do fumegante e permaneceu constante ao longo do tempo. Durante o período de expurgo, as médias da temperatura $\left(21^{\circ} \mathrm{C}\right)$ e umidade relativa do ar (66\%) estiveram dentro das recomendações (LORINI et al., 2007).

Os pontos plotados na figura 1 representam as observações originais. São dez repetições para 


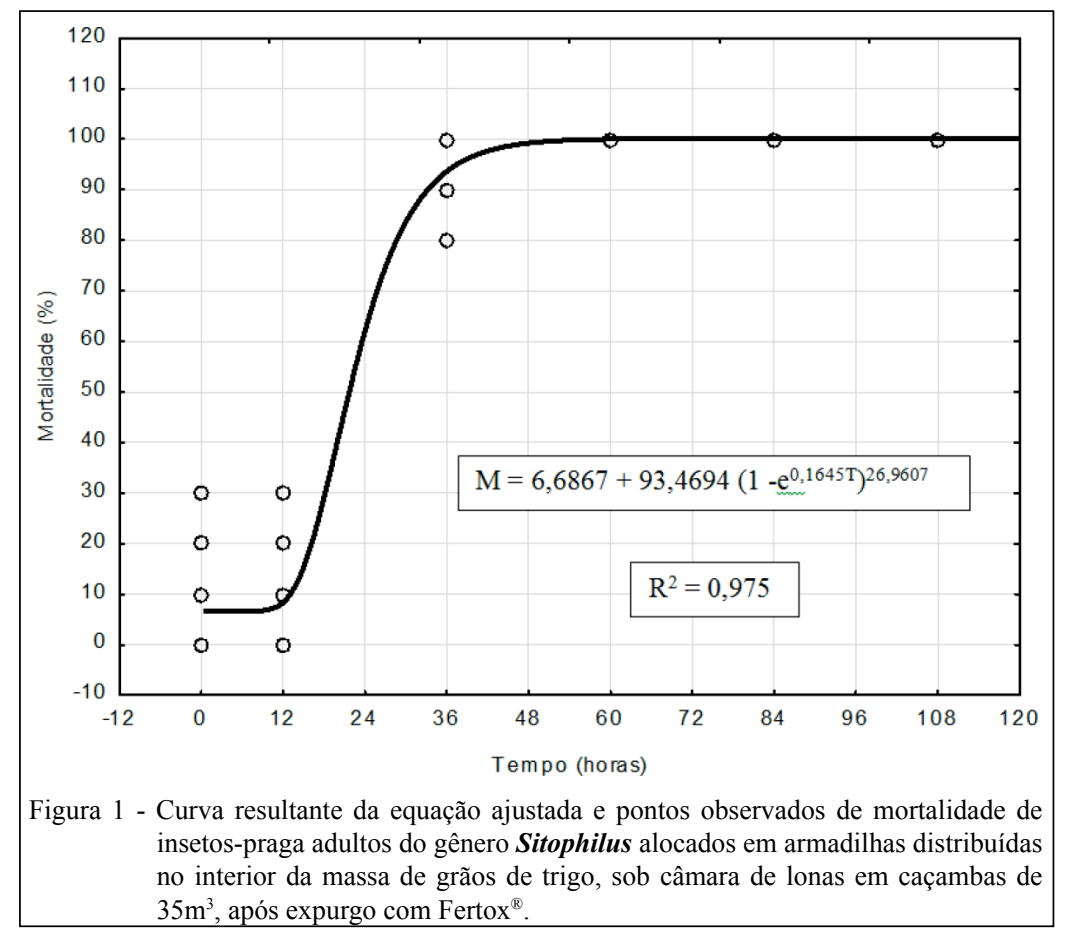

cada tratamento; entretanto, nos tratamentos zero (testemunha) e $12 \mathrm{~h}$, seis valores ficaram sobrepostos, correspondendo a $0 \%$ de mortalidade dos insetos. No tratamento $36 \mathrm{~h}$, seis resultados estavam sobrepostos, correspondendo a $100 \%$ de mortalidade. A partir de $60 \mathrm{~h}$, todos os valores permaneceram sobrepostos com $100 \%$ de mortalidade.

A equação demonstra que 58,9h após expurgo de grãos de trigo em câmara de lona a mortalidade dos insetos foi de $100 \%$. Os resultados apresentaram menor quantidade de horas de expurgo que as $72 \mathrm{~h}$ recomendadas por FARONI \& SILVA (2000), 96h indicadas pela bula do produto comercial Fertox $^{\circledR}$ (SEAB, 2013) e as $120 \mathrm{~h}$ obtidas por LORINI et al. (2011) para pragas de grãos armazenados.

Conclui-se que 58,9h após a aplicação de fosfina pode-se realizar a abertura da câmara de lonas, alcançando a mortalidade total de insetos adultos de Sitophilus dentro da massa de grãos de trigo.

\section{INFORME VERBAL}

ZANIKOSKI, L.J. Informe sobre classificação de grãos no pátio de triagem do Porto de Paranaguá. Gerente PSC CODAPAR, PARANAGUÁ, PR. Avenida Ayrton Senna da Silva, 161- D. Pedro II - 83203-800 - Paranaguá - PR. E-mail: (luciano@codapar.pr.gov.br).

\section{REFERÊNCIAS}

BERTUSSI, M.A. Fumigação em portos, aeroportos e fronteiras - legislação e procedimentos. Biológico, v.70, p.99-
100, 2008. Disponível em: <http://dx.doi.org/10.1016/S0022474X(00)00016-3>. Acesso em: 20 jul. 2013.

BRASIL - Ministério da Agricultura, Pecuária e Abastecimento. Regulamento de defesa sanitária vegetal. Rio de Janeiro: Governo da República dos Estados Unidos do Brasil, 1934. 555p.

BRASIL - Ministério da Agricultura, Pecuária e Abastecimento. Manual de procedimentos para tratamentos fitossanitários com fins quarentenários. Brasília: MAPA, 2006. 68p.

CODAPAR - Companhia de Desenvolvimento Agropecuário do Paraná. Legislação. Disponível em: <http://www.codapar.pr.gov.br/modules/ conteudo/conteudo.php?conteudo=78>. Acesso em: 27 abr. 2015.

FARONI, L.R.A; SILVA, J.S. Manejo de pragas no ecossistema de grãos armazenados. In: SILVA J.S. (Org.). Secagem e armazenagem de produtos agrícolas. 2 ed. Viçosa: UFV, 2000. p.345-382.

LIMA JÚNIOR, A.F. et al. Controle de pragas de grãos armazenados: uso e aplicação de fosfetos. Revista Faculdade Montes Belos, v.5, p.180-194, 2012. Disponível em: <http://revista.fmb.edu.br/index. php/fmb/article/view/72/65>. Acesso em: 10 set. 2013.

LORINI, I. et al. Detection and characterization of strong resistance to phosphine in Brazilian Rhyzopertha dominica (F.) (Coleoptera: Bostrychidae). Pest Management Science, v.63, p.358-364, 2007. Disponível em: <http://onlinelibrary.wiley.com/ enhanced/doi/10.1002/ps.1344>. Acesso em: 10 jul. 2013. doi: $10.1002 /$ ps. 1344 .

LORINI, I. et al. Monitoramento da liberação do gás $\mathrm{PH}_{3}$ por pastilhas de fosfina usadas para expurgo de sementes. Informativo Abrates, v.21, p.57-60, 2011. Disponível em: $<$ http://www.alice. cnptia.embrapa.br/alice/bitstream/doc/916899/1/artigo07.pdf $>$. Acesso em: 12 jul. 2013. 
RICHARDS, F.J. A flexible growth function for empirical use. Journal of Experimental Botany, v.10, p.290-301, 1959. Disponível em: <http://jxb.oxfordjournals.org/content/10/2/290. abstract> . Acesso em: 16 jul. 2013. doi: 10.1093/jxb/10.2.290.

SEAB - Agrotóxicos no Paraná. Fertox. Disponível em: $<$ http:// www.agricultura.pr.gov.br/arquivos/File/defis/DFI/Bulas/ Inseticidas/FERTOX.pdf>. Acesso em: 14 jun. 2013.

SOUZA, A.R. et al. Seleção e desenvolvimento de Sitophilus oryzae (Linné, 1763) em três substratos. Magistra, v.24, p.160-
163, 2012. Disponível em: <file:///E:/IMAGENS/11\%20-\%20 Seleo $\% 20 \mathrm{e} \% 20$ desenvolvimento $\% 20 \mathrm{de} \% 20$ Sitophilus $\% 20$ oryzae $\% 20$ Linn $\% 201763 \% 20$ em $\% 20 \operatorname{trs} \% 20$ substratos.pdf>. Acesso em: 12 jul. 2013.

STRELEC, I. et al. Spectrofluorimetric, spectrophotometric and chemometric analysis of wheat grains infested by Sitophilus granarius. Journal of Stored Products Research, v.50, p.4248, 2012. Disponível em: <http://www.sciencedirect.com/science/ article/pii/S0022474X1200032X>. Acesso em: 18 jul. 2013. doi: 10.1016/j.jspr.2012.04.004. 